Acta Hispanica (2018) 23: 201-212

\title{
ANTE EL DOLOR DE LOS DEMÁS: PROPUESTAS LITERARIAS DE RODRIGO REY ROSA
}

\author{
ILINCA ILIAN
}

Universidad de Oeste de Timişoara

\begin{abstract}
Resumen: En su ensayo sobre las fotos de guerra, intitulado Ante el dolor de los demás (Regarding the Pain of Others, 2003), Susan Sontag llamaba la atención sobre el hecho de que mirar un acto real de crueldad transforma al que no puede intervenir a fin de aliviar el dolor de las víctimas en un espectador perverso. Interesado en explorar los mecanismos de las innumerables formas de violencia, el guatemalteco Rodrigo Rey Rosa busca el lugar más adecuado para mirar el dolor sin caer ni en el sensacionalismo cínico ni en la lamentación acusadora. Sus propuestas literarias, hechas desde una posición posnacional, presentan varias posturas existenciales que tienen como constante una ambivalencia marcada con respecto al país de proveniencia. Comentaremos las posiciones bosquejadas en las novelas Lo que soñó Sebastián (1994), El cojo bueno (1996), El material bumano (2009) y por fin Fábula asiática (2016), donde se apunta a la posibilidad de crear un hogar para la humanidad a nivel planetario, si bien el acercamiento a esta utopía supone una previa fase destructiva.
\end{abstract}

Palabras clave: Rodrigo Rey Rosa, narrativa guatemalteca, violencia, posnacionalismo, dolor

\begin{abstract}
In his essay about the war photos untitled Regarding the Pain of Others (2003), Susan Sontag argues that a person who look a real act of cruelty without being able to intervene in order to heal the pain of the victims becomes a perverse spectator. Interested in exploring the mechanisms of the countless forms of violence, the Guatemalan writer Rodrigo Rey Rosa looks for the most suitable place to regard the pain without going into the cynical sensationalism neither the accusing lament. His literary proposals, made from a post-national position, presents different existential attitudes, which have as a constant an ambivalence regarding the native country, Guatemala. We will comment the stances sketched it the novels Lo que soñó Sebastian (1994), El cojo bueno (1996), El material bumano (2009) and finally Fábula asiática (2016), in which it is pointed out the possibility to create a place like home for the humanity on the global level, even that path to that utopia supposes a previous destructive phase.
\end{abstract}

Keywords: Rodrigo Rey Rosa, Guatemalan narrative, violence, postnationalism, pain

Encarnación paradigmática del tipo de escritor "posnacional" o "extraterritorial", debido a sus largas estancias fuera de la Guatemala natal, Rodrigo Rey Rosa tiene asimismo la característica paradójica de ser, actualmente, el autor guatemalteco más conocido en el extranjero después de Miguel Ángel Asturias (y claro, si consideramos hondureño al escritor nacionalizado guatemalteco Augusto Monterroso). 
Los largos viajes de Rodrigo Rey Rosa por Europa, las estancias en Nueva York y sobre todo los períodos pasados en Tánger, donde descubrió su vocación literaria gracias al encuentro providencial con el escritor estadounidense Paul Bowles, así como sus frecuentes idas y venidas entre su país y otros territorios del mundo, no lo convierten no obstante en un escritor "apátrida", ya que Rey Rosa encuentra en su país una inagotable fuente de inspiración.

Sin embargo, este interés por la realidad nacional está compensada por una atracción igual de fuerte hacia otros escenarios narrativos, especialmente los que el autor conoce de forma inmediata: es sugestivo en este orden de ideas el título Tres novelas exóticas dado a la recopilación publicada en 2013, que reúne tres novelas cortas escritas en diversas etapas de su creación y cuyas acciones se ubican en Guatemala, Tánger y la India. El título no carece evidentemente de ironía, según lo evidencia la nota del autor: "Las novelas escritas por guatemaltecos son, por definición, exóticas. Las novelas guatemaltecas ambientadas en la selva del Petén, en África del Norte o en el sur de la India pueden no tener el encanto de lo extraño, pero deben llamarse, en rigor, exóticas" (Rey Rosa, 2013:251). Por otro lado, más allá de la ironía, el título encierra una indicación formal acerca de la perspectiva a-céntrica, ex-céntrica y aun exótica del autor, que, inevitablemente, tras la erosión del estado nacional y el desmoronamiento de las utopías políticas mundiales, comparte con sus colegas de generación la condición "posnacional".

El tema del carácter transfronterizo, posnacional, extraterritorial de la literatura latinoamericana actual (y de hecho de gran parte de la literatura mundial publica$\mathrm{da}$, traducida y promocionada por las grandes editoriales multinacionales) ya es un tema que viene discutiéndose desde más de una década en los medios académicos y literarios. Las propuestas teóricas de Francisca Noguerol, Bernat Castany Prado o Fernando Aínsa fueron a tal punto asimiladas que en 2014 Timothy Robbins y José Eduardo González decidieron emplear, al menos de forma provisional, el término de "escritores posnacionales" para la entera generación de los autores latinoamericanos que se afirman o maduran entre los años 1990 y $2010 .{ }^{1}$ En este

\footnotetext{
${ }^{1}$ Según estos críticos, la tendencia posnacional actual es una prolongación de los movimientos medio parricidas de los autores relacionados con McOndo y las manifestaciones parecidas del subcontinente, que principalmente sienten la herencia del boom, y especialmente su interés marcado por la definición de la identidad, como una carga agobiante. La realidad latinoamericana no cambió radicalmente desde McOndo (1996) hasta hoy, sino
} 
caso, no creo que lleve muy lejos considerar, enumerar o valorar los elementos de "extraterritorialidad" de la obra de Rey Rosa, o sea aquellas estrategias de cuestionamiento de una identidad nacional que, de todas formas, resulta dudosa en un mundo con tantas configuraciones (post)identitarias, muchas de ellas traumáticas. En cambio, sí resulta interesante encontrar los puntos de anclaje de un discurso que pone "la fuga de los marcos de comprensión dominantes, marcos en realidad de apropiación espacial - sea local, nacional o continental- 'al servicio de' la develación de la violencia contemporánea" (Rodríguez Freire, 2010), coincidiendo en este sentido, perfectamente con su admirado (y admirador) Roberto Bolaño.

Se puede decir entonces que la narrativa de Rey Rosa sigue una trayectoria zigzagueante, de acercamiento y distanciamiento cíclico con respecto al punto de referencia que es Guatemala y que estas entradas y salidas del marco ficticio representado por su país corresponden a una búsqueda de mayor calado, relacionada con la concepción de un espacio de escritura desde el cual fuera posible narrar la violencia, de una forma que evitase tanto la identificación como la indiferencia. Soslayando pues la cercanía cegata y la lejanía insensibilizadora, su escritura asume una perspectiva múltiple que conjuga puntos de vistas no solo distintos sino incluso irreconciliables, con el fin de atenuar, pero sin suprimir, las oposiciones rígidas formadas por los términos inocentes/culpables, consciencia/inconsciencia acerca del delito, participante/espectador al sufrimiento.

Tal búsqueda de una posición adecuada para narrar la violencia está determinada, en parte, por la situación - de cierta forma novedosa, ya que la literatura "posnacional" surgió desde pocas décadas, especialmente con la creación de las editoriales multinacionales- de un autor reconocido a nivel mundial que proviene no obstante de un país considerado antaño "exótico". En Ante el dolor de los demás (como se tradujo al español el título Regarding the Pain of Others, de 2003), Susan Sontag observaba (y denunciaba) el provincialismo "central" del Occidente avanzado, donde los medios publican con mayor frecuencia y mucha mayor naturali-

que solo se agudizaron algunas tendencias de la sociedad ya aprovechadas literariamente por estos autores (el neoliberalismo, las tecnologías etc.). Los autores que se afirman en los años 1990-2010 tienen, según Timothy Robbins y José Eduardo González, se forman en una cultura moldeada por cuatro rasgos esenciales: el peso mucho mayor de la cultura globalizada ante la cultura "local" o "nacional"; la cultura del Internet, donde los blogs desempeñan el papel jugado en el siglo XIX por la crónica modernista; el relativo apartamiento de la esfera política, que hace difícil su adscripción en la izquierda o en la derecha; y por fin la resistencia ante el discurso nacionalista y sus estrategias de control (7-10). 
dad fotos cruentas provenientes del Asia o del África (o países latinoamericanos menos desarrollados, podríamos añadir), en virtud de una práctica secular de exponer seres humanos exóticos, "de piel más oscura", mientras que se muestran menos proclives a la "presentación de nuestras propias víctimas de la violencia" (Sontag, 2003:57). Al aventurar una explicación para esta situación, Susan Sontag nota que "al otro, incluso cuando no es un enemigo, se le ve por alguien que ha de ser visto, no alguien (como nosotros) que también ve" (57). Aprovechando esta sugerencia, podemos decir que la situación del autor guatemalteco que pasó largas temporadas en el extranjero y que llegó a tener con su país relaciones ambivalentes, resultándole su espacio a la vez extraño y propio, es en este caso más complicada, por causa de su pertenencia doble tanto al espacio de los que son vistos como a los que ven el sufrimiento lejano. De aquí, tal vez, una continua búsqueda del mejor posicionamiento ante los asuntos violentos narrados y una experimentación audaz, a lo largo de su trayectoria, en lo que respecta la instancia narrativa.

Una de las más espectaculares posiciones es la mencionada en la novela escrita en 1994 Lo que soñó Sebastián donde el protagonista se construye una casa especial según un principio por lo menos insólito, que reza: "hacer todo lo posible por que, estando dentro, te sientas fuera" (Rey Rosa, 2015:6). El narrador no oculta el carácter metonímico de esta "casa" ficticia con respecto al país, y refiere el contraste entre la seguridad y la protección dada por una identidad nacional asumida de forma no problemática y la situación del ser "posnacional":

\footnotetext{
Pensó en las palabras de su padre cuando le mostró los planos de su nueva vivienda: «A mí no me haces vivir allí ni muerto». Un hombre, aunque fuera el más honrado -le había dicho-, necesita sentirse protegido. Era mala la inseguridad. Sólo un salvaje que no tuviera nada que perder podía vivir en tales condiciones. «O alguien tan moderno como tú», había agregado (34).
}

No es una casualidad que es el padre quien remarca la inhospitalidad de tal vivienda: la extraña casa de Sebastián encierra de hecho el rechazo del orden paterno, y los valores patrios incluidos, de parte de un hijo que abandona la ciudad para vivir en la selva de Petén, donde se entretiene leyendo tratados de ética, con la convicción de que "en este lugar apartado de todo uno podía soñar con ser un hombre justo, un hombre moral" (19). La decisión de prohibir la caza en su territorio es la manera de Sebastián de oponerse a la cultura violenta de su país, pero este intento de crear un espacio artificial de no violencia en una tierra habitada por unos vecinos cazadores de padre en hijos lleva inevitable- 
mente al fracaso. Poco a poco, Sebastián remodela su casa, añade rejas en las ventanas e instala sistema de alarmas, como prueba de la imposibilidad de mantener la postura "moderna" que le recriminaba su padre. El sueño de vivir en el interior de una cultura sin participar de sus valores se revela pues pura ilusión. Aun más, la firme determinación de Sebastián de no negociar en absoluto sus valores morales y de rechazar cualquier conato de identificación con sus próximos, lleva a la adopción de una postura indiferente, las penas de sus vecinos resultándole al final tan ajenas como las de unos personajes "exóticos" de otro continente.

En El cojo bueno, escrito también en los años noventa (la primera edición apareció en 1996), el repudio del orden paterno y con él de la tradición violenta del país de origen, cobra otro cariz, de cierta forma más trágico pero también más desdeñoso, ya que la no identificación con su estirpe se plasma en la decisión de abstenerse de tener hijos, o sea dejar de pactar con una humanidad cruel y miserable. Juan Luis, víctima de un secuestro perpetrado por sus ex colegas de colegio, llega a perderse el pie izquierdo, cortado sin piedad por sus raptores, porque su padre no reaccionó a tiempo ante las amenazas de estos. A pesar de su intento de olvidar y de alejarse del lugar del trauma, el pasado lo persigue: en Tánger, donde se había instalado con su joven esposa, Juan Luis encuentra a uno de sus victimarios, cuya presencia lo determina regresar a su país; vuelto aquí, reencuentra a otro, que está en libertad y que, detalle importante, se ha convertido en padre de familia y aparentemente ha evolucionado desde el punto de vista moral. En la obra de Rey Rosa la desconfianza ante las autoridades oficiales de la justicia es una constante y las investigaciones detectivescas se limitan a descubrir el criminal, sin denunciar públicamente su crimen (es lo que pasa en Piedras encantadas, Caballeriza, El material bumano y aquî). Juan Luis rechaza desde el inicio la idea del ajusticiamiento oficial, pero también la de la venganza, no tanto por una asimilación profunda de la doctrina cristiana del perdón, sino más bien por la radical negación de identificarse con todo un orden paterno, en que está inscrito la injusticia y la crueldad. Observa Ignacio Echeverría:

En tanto que acto reparador, la venganza delata el afecto a una entidad de tipo personal, familiar, tribal, nacional, religioso, político, lo mismo da, solo la escala varía [...] ¿Qué ocurre, sin embargo, si nada de eso adquiere valor para el vengador? (Echeverría, 2007:91). 
La revancha de Juan Luis, nuevo Edipo con quien comparte el dolor de la cojera provocada por un padre egoísta, consiste no en matar o castigar al padre (simbolizado por todos sus victimarios), sino en matar en sí al padre potencial, y con él toda participación afectiva concreta en un mundo regido por el mal. Juan Luis decide no reproducirse, mientras que uno de sus antiguos verdugos, ya recuperado después de una vida disipada, se enorgullece por sus logros en el orden familiar, que es de hecho un orden de la reproducción de la violencia patriarcal: "sus hijos le habían proporcionado muchas alegrías, le habían devuelto el amor a sus padres y a la respetabilidad" (Rey Rosa, 2013: 104). Queda abierta la pregunta si esta indiferencia superior, que conjuga una suerte de compasión abstracta y cierto desdén por los demás, fomenta una saludable indiferencia respecto a su propio trauma, o al contrario aviva el victimismo y, a través de él, la identificación con un país traumado.

Uno de los elementos nuevos que aparece en los libros de Rey Rosa publicados en los años 2000 es la irrupción en la narración de un personaje clave, que es propio autor, ficcionalizado a través de los procedimientos propios de la autoficción y la metaliteratura (Jossa, 2014:44). El material bumano (2009) es más bien una antinovela, formada por las notas sueltas tomadas por el narrador durante unos meses de 2005 cuando, por un permiso especial, consigue investigar en el Archivo de la Policía guatemalteca descubierto por azar gracias a una explosión ocurrida aquel año. El plan inicial del narrador, consistente en buscar informaciones sobre los artistas e intelectuales que tuvieron relaciones con la policía política del país, bien como víctimas, bien como colaboradores o delatores, se transforma a medida que avanza la (pseudo)acción en una reflexión acerca de la capacidad del escritor de contribuir a esclarecer el sentido de la historia nacional y de situarse de la manera más adecuada a fin de convertirse en, al menos, testigo si no juez en el complejo proceso de establecer la parte de culpa de unos amplios sectores de la sociedad guatemalteca durante la larga guerra interna que devastó el país entre 1960 y 1996. Rey Rosa manifiesta una loable circunspección con respecto a la capacidad revelatoria de la literatura y, por ende de los poderes de los escritores en opinar acerca de la culpabilidad y la justicia, pero el reconocimiento de la parcialidad, subjetividad y torpeza no es lo mismo que la impotencia total o el bloqueo. Lo que falta es, afortunadamente, la posición acusadora y la seguridad dada por una supuesta superioridad otorgada por el oficio del escritor capaz de detectar las verdades detrás de las mentiras oficiales, o sea los presupuestos postcolonialistas y antiimperialistas en que se funda gran parte de la "nueva novela histórica". El relativismo y el escepticismo de Rey Rosa no llega, evidentemente, a disculpar a los cri- 
minales, pero sí a la comprobación de la fluctuación de los criterios de elegir entre el bien y el mal no solo de una persona a otra sino de uno mismo en varias etapas de su vida:

\begin{abstract}
Zagajevski: Describir nuevas variedades del mal y del bien - he aqui la magna tarea del escritor [...] Y si las nuevas variedades llegaran a obliterar las viejas ideas del mal y del bien - de lo que pueden ser o llegar a ser en la subjetividad de cada uno, lo uno y lo otro? Aun el mejor de nosotros - pienso en el "nosotros" más amplio que me es posible- necesita elegir constantemente entre el mal y el bien. Entonces, se hace obvio que las elecciones no son nunca idénticas, ni pueden serlo, entre dos personas distintas, porque sus circunstancias -de tiempo y lugar por lo menos- son necesariamente distintas. Tiempo y lugar - ambos conceptos entendidos en toda su extensión; es decir: en su tendencia al infinito (Rey Rosa, 2009:84).
\end{abstract}

Ahora bien, esta incerteza moral, que en sí resulta saludable, se paga no obstante con un malestar interior por causa del cual, en el caso del narrador (y posiblemente del autor también), resulta imposible encontrar un lugar adecuado para vivir.

Guatemala presentada en este libro es un país corrupto hasta la médula, donde, con una negra ironía, los antiguos asesinos investigan en el Archivo de la policía, haciendo así de reparadores de los crímenes perpetrados por ellos mismos en el pasado, y donde, aun después de casi diez años desde la firma de la paz, en 1996, sigue habiendo homicidios, atentados, crímenes sin resolver y sin castigar. La identificación con tal país es, evidentemente, imposible, cuando de hecho el propio narrador es víctima de arbitrariedades varias: se le niega el acceso al Archivo cuando está en plena investigación, recibe llamadas telefónicas amenazadoras y vive en un clima de pánico semejante a un estado subfebril. A un conocido en París que le pregunta si se siente amenazado viviendo en Guatemala le responde: "decir que sí sería una exageración, pero negarlo sería faltar a la verdad" (132). A su nieto que vive en Italia le declara que "milagros aparte, no hay nada bueno que esperar", "las cosas van a empeorar mucho antes que mejoren" y le aconseja que "tal vez no hay que pensar en cómo cambiar las cosas, sino en cómo alejarse de todo eso" (131). Aun más, teme que, si las cosas continúan así, Guatemala compartirá el destino de Haití, "convertido prácticamente en un cementerio" (133). Por otra parte, se pregunta: 
Ante el dolor de los demás: propuestas literarias de Rodrigo Rey Rosa

\begin{abstract}
¿Pero en qué otro país podría vivir yo ahora? [...] la idea de emigrar de nuevo - ¿a los Estados Unidos, a Europa, a México, a Argentina, o aun al África? - no me parece razonable todavía. Es decir, no me siento suficientemente amenazado para emprender la fuga (139).
\end{abstract}

Si bien la idea de volver a exiliarse lo visita constantemente, la necesidad de vivir en Guatemala tiene mucho que ver con la calidad de padre, ya que su hija Pía, de cuya madre está separado, vive en este país. La investigación en el Archivo se puede ver entonces como un símbolo del compromiso con respecto al futuro del país en que tiene la descendencia, pero los obstáculos son importantes: el propio padre del narrador, cuya mujer había sido víctima de un secuestro en los años ochenta, ve con reticencia la actividad del hijo y aboga por el ruinoso status quo: "¿pero para qué escarbar en el pasado? Es mejor dejar que los muertos descansen, ¿no?” (83). Ni siquiera una tardía justicia lo seduce: "Les pregunto qué piensan que deberíamos hacer si ahora nos enteráramos de quiénes secuestraron a mi madre. Mi padre dice que haría lo mismo que hemos hecho hasta ahora: nada" (161). Además del impedimento psicológico representado por el padre, se destaca también la poca convicción del narrador, que desiste poco a poco a escribir una verdadera novela, al comprobar la imposibilidad de dar coherencia y articular en una trama tal abundancia de datos heterogéneos, cuya acumulación produce un efecto paradójico: "la inmensidad de mi ignorancia generalizada, cuyos horizontes, a medida que voy adquiriendo nuevos conocimientos, o atisbos de conocimientos, parecen más extensos cada día" (126-127). El fracaso del escritor es al mismo tiempo una auto acusación de cobardía y de ineptitud pero asimismo una bella prueba de humildad, que contrasta con la confianza exagerada de los escritores de hace pocas décadas y que se rinde, no sin un dejo de ironía, ante la eficacia de los nuevos medios, más directos pero asimismo menos matizados: "le digo [a un documentalista] que la idea de un documental en ciernes me hace querer dejar de escribir sobre el Archivo, que las cámaras harán mejor trabajo que yo" (178). Entre la identificación (fracasada) con un país marcado por la injusticia y la indiferencia (imposible) ante una historia de violencia continua, la posición del autor se superpone a la atribuida por la hija del narrador a su papá, cuando le sugiere el posible final de la historia que él intenta en vano contar:

- ¿Sabes cómo podría terminar? - me dice.

Niego con la cabeza.

-Conmigo llorando, porque no encuentro en ninguna parte a mi papá - responde. 
Su última novela, Fábula asiática (2016) continúa explotando el tema del lugar del escritor en un mundo donde la desigualdad se acrecienta cada vez más, pero esta vez el acento cae en la culpa compartida por todos y en la dificultad de encontrar la frontera entre los justos y los injustos, dado que a nivel global, y no solo entre los límites de un solo país como es Guatemala, se experimenta una sensación de impotencia ante la iniquidad arrolladora. El terrorismo, las amenazas del Estado Islámico y de tantos otros grupos revanchistas musulmanes, las olas migratorias que avanzan hacia Europa desde el África y el Oriente Medio, pero también la condescendencia de los grandes poderes ante los intentos de afirmación de alternativas provenientes de las zonas marginadas del planeta, todo esto se da cita en una novela que, si bien puede verse como una obra de reacción a la actualidad más inmediata, intenta proponer no tanto una solución sino una advertencia acerca de una globalización tecnológica y de una política armamentista que llegan a transformarse en un Uróborus autodevorador. Un musulmán tangerino, un griego ortodoxo y un guatemalteco, todos superdotados, están seleccionados por las grandes universidades norteamericanas para convertirse en astronautas de la NASA e integrarse así en la élite científica del planeta; confrontados con los problemas particulares de sus propios países, verbigracia el terrorismo musulmán y la llegada de los migrantes en las islas griegas, su inicial interés por integrarse en el magno proyecto universalista "central" se muda en un plan de minarlo por la destrucción del sistema de satélites artificiales que permiten el funcionamiento de Internet y las telecomunicaciones modernas. El antiguo malestar proveniente de la comprobación de que el avance tecnológico no redunda en ningún progreso moral transforma a estos jóvenes brillantes en unos anarquistas que se autodenominan, eufemísticamente, antiarmamentistas, ya que advierten la lógica fatal de una industria bélica suicida:

\footnotetext{
Para que [sus] economías no se desplomaran, los poderosos debían vender armas a sus propios enemigos, a quienes ya no podían controlar, y quienes ahora atentaban ¿por razones ideológicas? contra la vida de los habitantes de esos países con los medios que ellos mismos, los poderosos, habían fabricado. La imagen del suicidio colectivo de la raza humana cruzó por su cabeza (67).
}

En concordancia con una tradición simbólica que necesita la completación de la tríada por un cuarto término, a los tres jóvenes se les une, de modo contingente, el escritor mexicano Rubirosa (transparente avatar ficcional de Rey Rosa) que se ve merecedor de integrar la tripulación espacial destinada a destruir los satélites orbitales de la tierra gracias a un complejo de circunstancias fortuitas, donde él 
juega más bien el papel del naïf imprudente, pero también gracias a una intuición documentada en un pequeño ensayo intitulado precisamente "Fábula asiática". Alli él aventura la idea del suicidio colectivo como signo de humanidad en vez de la elección aparentemente razonable, ante un peligro mortal, de unos cuantos individuos que se supondría que serían capaces de perpetuar la especie y, con ella, sus valores. La concepción de los jóvenes anarquistas de que vale regresar a la Edad Media (como cree el musulmán Abdelkrim) o aun más a la edad de piedra (según el griego Xeno) a fin de forzar la humanidad a imaginar un trayecto superior desde el punto de vista moral es sin duda mucho más ambiciosa que el bosquejo de la situación imaginada en el ensayo escrito por el ficticio escritor Rubirosa; no obstante, este texto tiene un peso no transcendental, sino auxiliar, cooperante, al proyecto de destruir el orden mundial vigente que llevan a cabo los jóvenes científicos. No se trata de declarar el papel subalterno de las letras con respecto a la ciencia y tecnología (al fin y al cabo, los jóvenes se sirven de la tecnología y la ciencia para limitar precisamente los daños que éstas producen), sino de conjugar el arte y la ciencia en un proyecto que culmine en una utópica apocatástasis, como la soñada por Xeno (69), ya que el perdón de los malos de parte de los buenos se vuelve más fácil en un mundo de la culpa compartida. Además, la suspensión de las adscripciones nacionales, políticas, culturales y religiosas, pero sin la supresión de la diversidad, fomenta una identificación con la entera raza dolorida y excluye de por sí la indiferencia cínica. A la imposibilidad de ubicarse del escritor Rey Rosa en El material bumano responde en Fábula asiática una postura ecuménica que representa hasta la fecha la opción más conveniente del escritor guatemalteco ante el dolor de los demás, o sea de todos:

En lugar de escandalizarse por las ideas que los distinguían, el marroquí sunnita, el griego ortodoxo y el guatemalteco ateo habían tomado como punto de referencia el firmamento, en cuya relación podían parecer casi iguales (64).

El posicionamiento "fuera" / "adentro" como constituyente de la subjetividad, en la línea de análisis foucauldiana, ha sido analizado con provecho en la obra de Rodrigo Rey Rosa por Emanuela Jossa, que, gracias a este enfoque, ha señalado aspectos esenciales de la producción del escritor guatemalteco, verbigracia el paso de la estética onirista de su primera etapa de producción a una escritura más realista a partir de los años noventa; el diálogo polémico con el género testimonial, cuya proclamada veracidad cuestiona; la paulatina penetración en el relato, a partir de los años 2000, de "una reflexión acerca del quehacer del escritor: su trabajo, su responsabilidad, su función” (Jossa, 2014:39). A pesar de su 
hondo calado interpretativo y de sus valiosas intuiciones, es, creo, exagerado decir que "la narración de Rodrigo Rey Rosa no tiene el objetivo de mostrar verdades, develar misterios, establecer vencidos y vencedores: se trata más bien de reproducir los mecanismos de la violencia y sus repercusiones en la vida diaria" (44). El relativismo y el escepticismo de Rey Rosa no llegan a disculpar a los criminales, si bien a través de la multiplicación de los puntos de vista saca de relieve también sus aspectos humanos y su capacidad de evolucionar moralmente (como lo revela la historia del verdugo arrepentido de El cojo bueno). Asimismo, la revelación de los mecanismos de la violencia son a la vez una denuncia implícita, y la impotencia experimentada de muchos de sus personajes ante la injusticia, si bien renuncia al idealismo y puede inscribirse en una estética del cinismo, según lo sugiere Beatriz Cortez (2010:6), no representa necesariamente un consentimiento dado al cinismo como posición filosófica. Señalamos en este artículo la circunspección de Rey Rosa con respecto a la postura acusadora de los escritores que se autoidentifican con una suerte de jueces atemporales y proclaman su capacidad de revelar la verdad detrás de las así llamadas mentiras oficiales, o sea todo el fundamento conceptual de gran parte de la "nueva novela histórica" de la segunda mitad del siglo XX. Pero una desculpabilización total o una culpabilización general, indiferenciada, o sea la supresión de las diferencias entre "los vencidos y los vencedores" es difícil de argumentar, aun más cuando tal discurso saldría de los límites de la ética de la representación que, como muestran Goldberg y Moore, no puede soslayar preguntas con respecto a "cómo hacer justicia a la memoria de las víctimas del evento, cómo no seguir violentándolas mediante la espectacularización o erotización del sufrimiento, y cómo crear imágenes culturales que detengan el ciclo de revancha y violencia" (2012:9). Así como intentamos mostrar, en su entera obra Rey Rosa denuncia la diferencia entre los que "ven" y los que "están vistos", según la distinción de Susan Sontag mencionada al principio de este artículo, pero esta denuncia no está hecha desde una posición superior, justiciera, sino desde una postura que combina la negación del cinismo con la modestia de un escritor cuya confianza en los poderes de la literatura de mejorar el mundo, sin desaparecer por completo, se ha reducido bastante. La asunción de la culpa colectiva y una sana humildad serán pues unas interesantes propuestas morales avanzadas por el escritor guatemalteco a través de su literatura. 
Ante el dolor de los demás: propuestas literarias de Rodrigo Rey Rosa

\section{Bibliografía}

Cortez, Beatriz. 2010. Estética del cinismo. Pasión y desencanto en la literatura centroamericana de la posguerra. Guatemala: F\&G.

Echeverría, Ignacio. 2007. Desvíos. Santiago: Ediciones Universidad Diego Portales.

Goldberg, Elizabeth Swanson \& Alexandra Schultheis Moore. 2012. "Human Rights and Literature: The Development of an Interdiscipline." Theoretical Perspectives on Human Rights and Literature. Eds. Swanson \& Moore. New York: Routledge.

Jossa, Emanuela. 2014. "Adentro y afuera: lugares y fronteras en la obra de Rodrigo Rey Rosa”. Cabiers d'etudes romanes: Revue du CAER, 28. 33-46.

Rey Rosa, Rodrigo. 2009. El material bumano. Barcelona: Anagrama.

Rey Rosa, Rodrigo. 2013. Imitación de Guatemala. Madrid: Alfaguara.

Rey Rosa, Rodrigo. 2015. Tres novelas exóticas. Madrid: Alfaguara.

Rey Rosa, Rodrigo. 2016. Fábula asiática. Madrid: Alfaguara.

Robbins, Timothy, González, José Eduardo (Eds.). 2014. New Trends in Contemporary Latin American Narrative. Post-National Literature and the Canon. London: Palgrave Macmillan.

Rodríguez Freire, Raúl. 2010. "La orilla latinoamericana: sobre la literatura (extraterritorial) de Roberto Bolaño y Rodrigo Rey Rosa" Istmo: revista virtual de estudios literarios y culturales centroamericanos, 20 (enero-junio). 